\title{
Enfermedades otorrinolaringológicas en una población infantil aparentemente sana
}

\author{
Dr. Aliro Cotrea LI, Dra. Virginia Glinas H. 1
}

Otolaryngologic disease in children from charity homes

Among 363 children of both sexes aged 4 to 15 years otd and living in different charity homes at Santiago, Chile, 175 (48\%) showed evidence of significant ear, nose or throat disease. Most frecuent abnormalities were allergic rlinitis, hipoacusia, and tubarian malfunction. Chronic tonsillitis was infrecuently seen. Apropriate examination and timely diagnosis should avoid further cluronic otolaryngologic alterations in this children.

(Key words: Otolaryngologic diseases, ear, nose, throat).

En la literatura pediátrica y otorrinolaringológica (ORL), suele analizarse la frecuencia de ciertas afecciones especificas, tales como otitis media aguda o las infecciones respiratorias altas. Revisando el tema no hamos encontrado publjwaciones que consideren la totalidad de los problemas ORL en poblaciones infantiles chilenas.

Por ello decidimos estudiar el problema en un grupo de niños socialmente desvalidos.

\section{MATERIAL Y METODO}

Para realizar esta investigación se examinaron 363 niños provenjentes de djversas instituciones de caridad de Santiago, que mantienen hogares para nifos, los cuales son examinados regularmente por pediatras.

El único criterio de selección fue la edad, ya que para ingresar al estudio se exigió uлa mínima de cuatro años y una máxima de quince. Dentro de este rango, fueron examinados todos los nifros de cada institución.

1. Médicos del Departamento de Especialidades. División Ciencias Médicas Oriente. Facultad de Medicina. Universidad de Chile.
Para esto se diseñó una ficha tipo donde se registra. ron el peso, la talla y los antecedentes nutricionales del niño, todos los cuales resultaron dentro de los parámetros considerados normales.

Por las características de la muestra, no fue posíble obtener información relativa a los padres, embarazo y parto.

Luego se analizaron los antecedentes de afecciones otorrinológicas y pediátricas previas, descartándose todos los niños que fuesen portadores de una enfermedad crónica.

Se buscaron especialmente antecedentes de otorrea, hipoacusia, otitis repetidas, rinitis, mal.hábito respiratorio, amigdalitis y epistaxis, dejándose además la posibilidad al examinador para que agregase en el registro información no especificada. Se hizo en cada niño un examen clínico ORL.

Los niños con evidencias de algún trastomo, fueron sometidos a estudios adicionales para establecer un diagnóstico completo. Por último, cada niño enfermo recibió el tratamiento necesario.

\section{RESULTADOS}

Fueron examinados 363 niños ( 232 eran varones), cuya edad yariaba entre 4 y 15 años, con un promedio de 9,5 años y una desviación estándar de $\pm 3,45$. 
Al final del estudio se consideró que 175 niños (99 hombres) de la muestra tenían alguna afección ORL $(51,8 \%)$. Esta enfermedad, por su gravedad requeria tratamiento inmediato en 107 niños (63 hombres), representando un porcentaje del $61,1 \%$ de todos los enfermos. En cambio, el $38,9 \%$ restante (36 varones y 32 mujeres) necesitaban una atención susceptible de ser diferida.

En relación al tipo de enfermedades y edad, los resultados corroboran las afjrmaciones clásicas, de tal manera que no se considera de interés especificarlas. Sin embargo vale la pena destacar que el grupo etario con los trastornos más importantes correspondió a los nifros entre 4 y 10 años, sin diferencia significativa entre ambos sexos.

La distribución de ambos grupos de trastornos de aprecia en las Tablas I y 2.

En este grupo llama la atención el alto número de niños con rínitis alérgica, todos con prueba cutánea positiva, generalmente a pólenes o polvo habitación y dermatofagoides.

Tabla 1.

Enfermedadts ORL que requjeren tratamicnto inmediato en 363 nifios aparentemente sanos

\begin{tabular}{lrc}
\hline ripo de Trastor no & $\begin{array}{c}\text { Número } \\
\text { de casos }\end{array}$ & Porcentaje \\
\hline Rinitis alérgica & 30 & 8,2 \\
Secuela de otitis media & 11 & 3,0 \\
Otopatiá adliesiva & 4 & 1,1 \\
Hipoácusa & 32 & 8,8 \\
Fisura palatina** & 2 & 0,5 \\
Amigdalitis crónica & 7 & 1,9 \\
Bocio*** & 2 & 0,5 \\
Disfunción tubaria & 21 & 5,7 \\
Otitis media crónica & 9 & 2,4 \\
Rinitis atrófica & 4 & 1,1 \\
\hline
\end{tabular}

TOTAL

122

* No están incluidos los tapones de cerumen.

* Tratados pero no rehabilitados

*** Aunque no es una patología ORL propiamente tal.

**** Hay varios trastornos en un mismo giño.

Tabla 2.

Enfermedades ORL de importancia relativa, encontrada en 363 niños aparentemente sanos

\begin{tabular}{lcc}
\hline Tipo de trastorno & $\begin{array}{r}\text { Numero } \\
\text { de casos }\end{array}$ & Porcentaje \\
\hline Desviación septal & 30 & 8,2 \\
Papilomatosis de úvula & 4 & 1,1 \\
Tapón đe cérumen & 28 & 7,7 \\
Respirador buca! & 7 & 1,9 \\
Eccema de oídos & 2 & 0,5 \\
Orejas en asa & 2 & 0,5 \\
\hline TOTAL & 73 & \\
\hline
\end{tabular}

* No se considera a los niños con rinitis alérgica.

** Se consignan varias lesjones en un mismo niño.
Como se puede apreciar, en este grupo existen alteraciones cuya corrección es absolutamente opcional, como las orejas en asa, o discutible a futuro, como la desviación septal.

Los niños con desviación septal, papilomatosis y tapones de cerumen estaban todos asintomáticos. Los enfermos con eczema, tenjan prurito en los oidos. Entre los respiradores bucales, se encontró un crecimiento patológico de las adenoides en tres de ellos. Los cuatro restantes tenian rinomanometráas, estudios de rinofaringe $y$ pruebas cutáneas normales, por los que se les consideró portadores de mal hábito

Tjenen especial interés por su frecuencia $y$ consecuencias los pacientes con hipoacusia, por ello se les analiza en forma independiente (Tabla 3).

Tabla 3.

Etiología de 58 hipoacusias encontradas en 363 лілоs aparentemente sanos

\begin{tabular}{lc}
\hline Hipoacusios de transmisión: & 41 casos \\
Otitis media secretora & 15 \\
Secuela de Otitis media & 11 \\
Otopatía adhesiva & 4 \\
Fisurados & 2 \\
Otitis media crónica & 9 \\
& \\
Hipoacusias sensorioneurales: & 17 casos \\
Post meningitis & 5 \\
Post TEC & 2 \\
No precisada & 10 \\
\hline
\end{tabular}

En este grupo no se incluye a los pacientes con una disfunción tubaria, los que no son, la mayoría de las veces, hipoacúsicos propiamente tales, pero pueden llegar a serlo.

\section{COMENTARIO}

En el análisis de nuestro material, llama la atención el alto número de pacientes con rinitis alérgica, hecho importante ya que esta enfermedad puede dar origen a trastornos graves, especialmente en el oido. Muchos de estos pacientes inician una disfunción tubaria que con el tiempo provoca alteraciones en la fisiología del oido medio, culminando el proceso con una otopatía adhesiva, afección caracterizada por atelectasia timpanica acompañada de destrucción variable de la cadena osicular. Las consecuencias de la rinitis alérgica ya se aprecian en el grupo, con $1,1 \%$ de otopatias adhesivas y un $8,2 \%$ dé disfunciones tubarias.

También debe preocuparnos el porcentaje de secuelas de otitis media, enfermedad evitable con un tratamiento adecuado y que lleva a una hipoacusia de grado variable al distorsionar la anatomía del oído medio. Fue sorprendente el 
bajo número de otitis media crónica, ya que de acuerdo a estudios nacionales ${ }^{1}$ su incidencia debió ser mucho más alta. Podemos concluir entonces que esta afección se diagnostica bien en nuestro medio.

En cambio no nos sorprendió la cifra de amigdalitis crónica, más bien baja, ya que al parecer es una afección en retirada, quizás por el uso adecuado de antibióticos. ${ }^{2}$ Es importante mencionar que de los 363 niños examinados, sólo había dos amigdalectomizados, de tal manera que la cifra anterior no puede atribuirse al hecho de haberse efectuado el tratamiento adecuado.

En relación a los nitios con hipoacusia, debemos aclajar que en ningún caso esta era severa y que probablemente por eso no fueron diagnosti. cadas. Sin embargo, todo niño hipoacúsico es en cierta forma minusválido ${ }^{3}$ y por lo tanto siempre debe ser detectado y tratado ${ }^{4}$. Esto es más importante si consideramos que la mayoria de las hipoacusias era de transmisión (compromiso de] oido medio) las que en la actualidad pueden corregirse. En el grupo de niños con hipoacusia sensorioneural, destaca el número de casos sin etiología precisa, y que "a posteriori" este diagnóstico etiológico es muy difícil de realizar, especialmente si no hay antecedentes confiables del paciente ${ }^{5}$.

Estos resultados están demostrando la importancia del examen ORL en la población infantil. Las enfermedades de esta esfera no sólo son frecuentes si no que también sus consecuencias posteriores son serias y muchas veces evitables. $\mathrm{Si}$ bien el grupo estudiado corresponde a un estrato peculiar, $y$ la proyección a todo el universo pediátrico nacional sería discutible, no es menos efectivo que el grupo representa al sector más desvalido de nuestros niños y por lo tanto el que más necesita de nuestra atención.

Es igualmente importante destacar como una atención peđiátrica orientada a la búsqueda de estas afecciones puede a través del diagnóstico precoz, evitar muchas complicaciones.

Finalmente, estos resultados deben hacer meditar sobre la necesidad de una correcta capacitación mediante programas docentes adecuados a nivel de pre y post grado.

\section{RESUMEN}

Se describen las enfermedades ORL encantradas en una población infantil constituida por 363 niños sanos (232 varones) cuya edad varía entre 4 y 15 años. Destaca el alto número de nif̂̃os còn rinitis alérgica o hipoacusia, inadvertidas en el examen pediátrico rutinario. Se discute la importancia del correcto manejo diagnústico de estos trastornos pues evita alteraciones más graves a futuro. \$ comenta la baja incidencia de algunas enfermedades anteriormente muy comu. nés, como la amigdalitis crónica. Finalmente se enfatiza lo importante que es capacitar adecuadamente al médico en el manejo del diagnóstico de estas afecciones por su alta frecuencia en la población infantil.

\section{REFERENCIAS}

1. Otte, $\boldsymbol{J}$. et al: Investiga ción de algunos problemas de la atitis media crónica en Chile. Revista de Otorrjnolaringología (Chile) 33: 1, 1973.

2. Sasaki. C.T. and Kos, N.: Cluronic bacterial tonsillitis: F'act or Fiction. Otolaryngology, 86: 856 , 1978.

3. Whatson, C.S.: Time course of auditory perceptual learning. Ann Otol Rhinol Laryngol, 89: 96, 1980.

4. Javel. E.: Neurophysiological correlates of auditory maturation. Ann Otol Rhinol Laryngol $89: 103$, 1980.

5. San Martin, R., Carvajal, $T$, y Sinchez, $S$ : Contsjbución al estud io etiológico de la sordera en el niño. Revista de Otorrinoluingología (Chile), 30: II, 1970. 